\title{
PREPOSIÇÕES INTRODUTORAS DE ORAÇÕES INFINITIVAS EM PORTUGUÊS BRASILEIRO
}

\author{
PREPOSITIONS INTRODUCING INFINITIVAL \\ CLAUSES IN BRAZILIAN PORTUGUESE
}

\author{
Daniel De Brito Machado \\ Universidade de Brasília, Brasília, Distrito Federal, Brasil \\ danielmachb@gmail.com
}

Resum0: Este artigo tem como objetivo discutir a análise tradicional de marcador de Caso para as preposições gramaticais/funcionais no âmbito da Teoria Gerativa, bem como investigar as suas propriedades semânticas e sintáticas em contextos de oração infinitiva, em oposição aos contextos de complementação por sintagma determinante. Já se demonstrou em trabalhos anteriores (SALLES, 1992; MACHADO, 2013) que a preposição introdutora de oração infinitiva em contexto de complementação está mais sujeita a flutuações entre a preposição de e em e, por vezes, com do que a preposição que licencia o sintagma determinante. Dessa forma, este artigo toma como base essa diferença de comportamento gramatical para reforçar as análises de não marcação de Caso em relação às preposições diante de orações não finitas, estendendo a análise à preposição para, que carrega uma semântica específica nesses mesmos contextos.

Palavras-chave: (Flutuação de) Preposição; Oração Infinitiva; Caso; Complementação

Abstract: This article aims to discuss the traditional analysis of Case marker regarding the socalled grammatical/functional prepositions in the Generative Theory, as well as investigate their semantic and syntactic properties in contexts of infinitival clause, in contrast with contexts of complements expressed by determiner phrases. It has been already demonstrated in previous works (SALLES, 1992; MACHADO, 2013) that the preposition introducing an infinitival clause is more available to fluctuation between the prepositions de 'of' and em 'in' (and, in some examples, com 'with') than the ones which introduce complements expressed by determiner phrases. Thus, this article takes this difference on the grammatical behavior of prepositions in order to reinforce the notion of non-Case markers regarding the prepositions in contexts of infinitival clauses; besides, we extend the analysis to the preposition para 'to', which carries a specific meaning in these same contexts.

Keywords: (Fluctuation of) Preposition; Infinitival Clause; Case; Complementation 


\section{INTRODUÇÃO}

Este artigo tem como objeto de estudo as preposições complementadoras que encabeçam os sintagmas oracionais no português brasileiro, a saber: de, em, com e para. Como observado em Salles (1992) e em Machado (2013), em português, as preposições de, em e com que introduzem orações infinitivas podem flutuar com mais facilidade do que as que encabeçam sintagmas determinantes (doravante DPs), como ilustram os exemplos a seguir:

(1) a. Tenho interesse em/*de inglês.

b. Tenho interesse em/de estudar inglês.

(2) a. Maria está surpresa com a festa.

b. Maria está surpresa em/ de/com ter uma festa só para ela.

Admitindo-se que as preposições que encabeçam os DPs em (1a) e (2a) são funcionais, como proposto em Chomsky (1986) e que as orações infinitivas em (1b) e (2b) têm a mesma distribuição de DPs, pressupõe-se que as preposições que encabeçam as orações infinitivas são também funcionais. Dessa forma, se, em ambos os contextos, a preposição que aparece tem, em princípio, o mesmo estatuto, como explicar que, em (1a) e (2a), a preposição é invariável, enquanto os contextos (1b) e (2b) permitem flutuações? Ademais, é importante considerar o fato de que, em contextos de complementação infinitiva, podem ser licenciadas preposições que não aquelas que ocorrem diante de sintagmas determinantes, como observado no contraste dos exemplos (1a) e (2a) em relação a (1b) e (2b), constatação que nos leva à hipótese inicial de que a preposição funcional tem estatutos diferentes a depender do ambiente, se nominal ou infinitivo.

Esse debate é de grande importância, no sentido de que é largamente admitido na teoria linguística gerativista que preposições funcionais são realizadoras/marcadoras de Caso (CHOMSKY, 1986; OUHALLA, 1994; NUNES, 2008; entre outros). Partindo desse pressuposto, infere-se que as preposições complementadoras de orações infinitivas são também realizadoras de Caso. Assim, surge um problema: se a preposição é marcadora de Caso nos dois contextos observados, por que apresenta comportamentos diferentes nesses dois ambientes?

A partir dessa constatação, qual seja, a de que as preposições de, em e com em ambientes de complementação infinitiva (cf. sentenças (b) acima) se comportam de maneira distinta de quando introduzem DPs (cf. sentenças (a) acima), este último contexto tradicionalmente associado à marcação de Caso, defendemos que (i) as preposições em contextos de orações infinitivas não são marcadoras de Caso, pois seria esperado, para tanto, comportamento idêntico nos dois ambientes, e (ii) tais preposições funcionam como licenciadoras de oração infinitiva e lexicalizadoras de traços em C, na linha do que já foi proposto em Kayne (2000) e Salles (2007).

Organizamos este artigo da seguinte forma: nas seções 1 e 2, revisamos duas análises prévias em relação às preposições funcionais em ambientes de complementação - na seção 1 , discutimos a análise de Kayne (2000), o qual já questiona o papel de marcador de Caso para tais preposições e, na seção 2, apresentamos o trabalho de Salles (2007), que retoma o questionamento de Salles (1992) quanto ao papel de marcador de Caso das preposições em complementação infinitiva e aborda mais especificamente em relação à preposição para, atribuindo não apenas o papel de licenciador de infinitivo a essa preposição, mas discutindo aspectos sintáticos e semânticos dos traços formais relacionados a ela. Na seção 3, estendemos parte da análise produzida por Salles (2007) em relação à preposição para às preposição de, em e com, a fim de demonstrar que essas preposições carregam traços que se afastam de uma hipótese de marcação de Caso. Destacamos que, para a análise feita neste artigo, não nos 
comprometemos com aspectos da derivação das sentenças com complementação infinitiva, em particular os relacionados a movimento da preposição, de modo que a análise em Kayne (2000) nos será relevante apenas no que concerne aos traços categoriais relacionados à preposição em italiano e que podem trazer luz à discussão para o português brasileiro.

\section{A ANÁLISE DE KAYNE (2000): PREPOSIÇÕES FUNCIONAIS COMO LICENCIADORES DE ORAÇÃO INFINITIVA}

Kayne (2000) analisa as preposições introdutoras de oração em italiano e classifica esses itens funcionais como licenciadores de oração infinitiva, seguindo a análise de Raposo (1987). Ademais, Kayne (2000) defende que a preposição introdutora de oração infinitiva não é marcadora de Caso pelo fato de o infinitivo ser uma categoria do tipo NP, e não DP. Nesse aspecto, Kayne (2000) diverge de Raposo (1987), demonstrando que, em italiano, a oração infinitiva pode ocorrer como complemento de nomes e adjetivos, os quais não atribuem Caso, como em (3), retirado de Kayne (2000, p. 284):

(3) Sono certo esser tu migliore.

Estou certo estar tu melhor.

'Eu estou certo de que você está melhor.'

A partir dessas considerações, Kayne (2000) adota a distinção entre NP e DP, tal como formulada em Abney (1987), postulando que as propriedades nominais do infinitivo estão codificadas na projeção NP. Além disso, assume que o Caso é exigido por DPs, e não por NPs, o que permite dispensar a vinculação entre a preposição introdutora da oração infinitiva e o Caso, já que, para ele, apenas DPs exigem Caso, enquanto NPs dispensam Caso.

Dessa maneira, de acordo com Kayne (2000, p. 286), a preposição, nesses contextos infinitivos, funciona como núcleo sintático complementador, que introduz orações infinitivas independentemente de o verbo selecionar ou não preposição. O autor lança mão de exemplos em francês para corroborar sua ideia, como demonstrado em (4). Observamos, nas traduções em português, que o contraste é o mesmo:

(4) a. Jean a oublié ses gants.

'João esqueceu suas luvas.'

b. Jean a oublié *(de) mettre ses gants.

'João esqueceu de colocar suas luvas.'

Dessa forma, o autor acredita ser possível confirmar a ideia de que a preposição introdutora da oração infinitiva não é selecionada pelo verbo, mas pela oração infinitiva, como uma manifestação morfológica para o licenciamento da oração infinitiva.

Kayne (2000, p. 284) sustenta a hipótese de que o infinitivo é uma categoria nominal com base nos exemplos em português, encontrados em Raposo (1987), em que a preposição

\footnotetext{
1 O verbo esquecer em português, assim como lembrar, recordar pode ocorrer como pronominal ou não. No primeiro caso, o complemento é obrigatoriamente preposicionado - me esqueci $*(d)$ isso, ela se esqueceu $*(d) a$ gente. No segundo caso, a preposição pode ou não ocorrer diante de DPs, embora com leve mudança de sentido eu esqueci o dinheiro, eu esqueci do dinheiro -, em que, para o complemento sem preposição, existe a ideia de 'esqueci o dinheiro em algum lugar' e, para o complemento com preposição, existe a de 'não me lembrei do dinheiro', ou mesmo ‘não levei em consideração', e, diante de infinitivo, ocorre obrigatoriamente com preposição - a gente esqueceu *(de) ir te ver.
} 
introdutora de infinitivo é obrigatória apenas quando seguida de nome e adjetivo (cf. (5a) e (5b)), não ocorrendo quando seguida de verbo (cf. (6c)):

(5) a. desejo *(de) cantar

b. desejoso *(de) cantar

c. Ela deseja cantar

Ademais, Kayne (2000, p. 286), sob o ponto de vista translinguístico, observa que, em italiano, os infinitivos não podem ser introduzidos por preposições diferentes de à/a e de/di, conforme demonstram os exemplos em (6):

(6) a. Contavo *su/di essere onesto.

Contava sobre/de ser honesto.

'Contei com ser honesto.'

b. *La sua fortuna consiste *in/di avere molti amici.

A sua fortuna consiste em/de ter multos amigos

'A sua fortuna consiste em/de ter muitos amigos.'

O que os exemplos acima demonstram é que, embora em outros dados possa haver coincidência entre a preposição selecionada pelo verbo e a que introduz uma oração infinitiva, a oração infinitiva pode selecionar uma preposição diferente daquela que o verbo seleciona diante de sintagmas determinantes, no caso, a preposição $s u$ em (6a) para o verbo contare e a preposição in em (6b) para o verbo consistire. Dessa forma, o autor sugere que a preposição aparece nesses contextos por motivos distintos aos de marcação de Caso e propõe que se trata da manifestação morfológica de algum traço da oração infinitiva ou que o verbo e o nome selecionam. Vale ressaltar que os exemplos em (6), do italiano, podem ser comparados aos dados do português, já que a preposição introdutora do DP não é necessariamente aquela que aparece no contexto de oração infinitiva, conforme observamos nos dados em (1), os quais abriram este artigo e apresentaram o problema da pesquisa.

Ademais, os dados acima corroboram a ideia de que a preposição em contexto de oração infinitiva não é marcadora de Caso e se assemelha a um núcleo funcional do tipo complementador. Kayne (2000, p. 289) reforça essa ideia ao observar que, no italiano, as orações infinitivas subjetivas não são introduzidas por preposição, mesmo quando aparecem numa ordem em que se esperaria a oração completiva (cf. (7c)), enquanto as preposições introdutoras de orações infinitivas em configuração inacusativa, quando o sujeito é um argumento interno subjacente, são obrigatórias, isto é, aparecem independentemente da posição em que a oração ocorre (cf. (7d)):

(7) a. (*Di) cercarlo comporta dei rischi.

(De) procurar ele comporta os riscos.

'Procurá-lo traz/comporta riscos.'

b. (*Di) cercarlo, credo che comporta dei rischi.

(De) procurar ele, creio que comporta os riscos

'Procurá-lo, creio que comporta/traz riscos.'

c. Comporta dei rischi $(*$ di) cercarlo.

Comporta os riscos (de) procurar ele.

'Comporta/traz riscos procurá-lo.'

d. *(Di) rimanere, credo che no gli è stato chiesto. 
(De) ficar, creio que não lhe sabe estado pedido.

'Creio que não lhe foi pedido.'

De acordo com os exemplos em (7), a preposição não pode licenciar orações que funcionam como sujeito em italiano, mesmo quando estão em ambientes pós-verbais, o que se poderia supor já que essa é uma posição típica de complemento nessa língua. No entanto, com verbos inacusativos, a preposição se mostra obrigatória, mesmo quando a oração aparece na posição canônica de sujeito, pré-verbal (cf. (7d)). Esse fato é particularmente interessante, pois verbos inacusativos são tradicionalmente conhecidos como aqueles que apenas projetam um argumento interno, o que sugere que a preposição introdutora de oração infinitiva tem estreita ligação com a manifestação dos traços de complemento em italiano. Fosse ela manifestação de Caso, seria esperado comportamento uniforme para sua lexicalização, algo que não se observa nos dados acima.

Assim, Kayne (2000), especificamente em relação ao italiano, defende a hipótese de que a preposição carrega traços diversos aos de marcação de Caso, quando apresenta os dados em (6), em que a preposição que licencia a forma não finita não coincide com a que é exigida diante de sintagmas determinantes, e aqueles em (7), em que, pela estrutura dos verbos inacusativos, é possível supor uma estreita ligação entre os traços de complementador e aqueles da preposição.

\section{O ESTUDO DE SALLES (2007): PREPOSIÇÕES INTRODUTORAS DE ORAÇÕES COMPLETIVAS INFINITIVAS NO PORTUGUÊS BRASILEIRO}

Salles (2007) analisa contextos em que a preposição aparece em ambiente infinitivo, considerando especialmente aqueles em que há realização lexical do sujeito da oração subordinada em referência disjunta ao da oração matriz, como se vê nos dados em (8), retirados de Salles (2007, pp. 8 e 9):

(8) a. Meu partido vai defender do voto ser aberto.

b. Maria disse para eu/mim lavar o carro.

A proposta que a autora apresenta para a análise das construções em (8) é a de que a preposição está no domínio do complementador (doravante, $\mathrm{C}$ ), associado à finitude. Tal análise vem da postulação de que $\mathrm{C}$ é uma categoria funcional, que carrega traços tanto de força ilocucionária quanto de finitude (cf. Rizzi, 1997), como apresentando na estrutura em (9) - cf. Salles (2007, p. 2):

(9) $\left[\mathrm{CP}_{\text {force }} /\right.$ tipo de oração $\ldots\left[\mathrm{CP}_{\text {fin }} \ldots\right.$

Dessa forma, de acordo com a autora, enquanto o CP mais alto é analisado como o locus para a codificação de orações introduzidas por que e se, o núcleo mais baixo é o locus para a introdução de preposições ditas complementadoras.

O estudo de Salles (2007) investiga a hipótese de que a preposição complementadora é uma categoria licenciadora da referência disjunta do sujeito da oração encaixada em relação ao sujeito da oração matriz, em dados como (8b), em que a preposição é obrigatória. Esse fenômeno é referido nos estudos gerativistas como efeito de obviação, que é a possibilidade de licenciamento da referência disjunta do sujeito dos dois predicados. Segundo a autora, a preposição para seria, portanto, um marcador do efeito de obviação no português brasileiro, conforme se depreende do contraste entre (10a), retirado de Salles (2007, p. 10), e (10b), em 
que, na ausência da preposição, o sujeito da oração infinitiva é correferencial em relação ao sujeito da oração principal.

(10) a. Maria disse aos rapazes para lavar(em) o carro

b. Maria $\mathrm{i}_{\mathrm{i}}$ disse ${ }_{\mathrm{i}}$ lavar o carro.

Ainda, a preposição pode ocorrer com o verbo querer (cf. Salles, 2007, p. 10):

(11) a. Quer para mim buscar o livro no depósito?

Ademais, os dados em (12) abaixo, extraídos de Salles (2007, pp. 8 e 9), nos mostram que, muito embora a seleção da preposição possa ser diferente, conforme demonstrado também por Kayne (2000) para o italiano (cf. (6)), há uma coincidência entre o uso obrigatório/opcional da preposição complementadora e a transitividade do verbo. Verbos que selecionam complemento preposicionado podem acompanhar a mesma preposição complementadora como introdutora da oração infinitiva, a qual flutua geralmente com as preposições $d e$ e em, enquanto verbos que não exigem complemento preposicionado tornam o uso da preposição complementadora opcional:

(12) a. Maria depende do rapaz lavar o carro. (depender de algo)

b. Maria concorda com o/do rapaz lavar o carro. (concordar com algo).

Como se pode extrair dos dados acima, verbos que exigem complemento nominal preposicionado também selecionam preposição diante de oração infinitiva, embora, no contexto de oração infinitiva, a preposição possa flutuar com outras (cf. 12, b).

Como observado em (11a), retomado em (13b), Salles (2007, p. 9) ${ }^{2}$ apresenta exemplos com o verbo 'querer' na oração matriz e em que aparece a preposição para, mas essa preposição não é selecionada pelo verbo:

(13) a. Os pais não querem pras filhas casar cedo, né...

b. Quer pra mim buscar o livro no depósito?

Salles (2007) defende a ideia de que os casos em (13) se assemelham ao de (8b), pelo fato de a preposição para ser um marcador da modalidade irrealis em $\mathrm{C}$, já que existe a contraparte finita para todos esses casos, em que o verbo é flexionado no modo subjuntivo, como se vê em (14):

(14) a. Os pais não querem que as filhas casem cedo, né...

b. Quer que busque no depósito?

Salles (2007, p. 13) ainda demonstra que o uso da preposição para tem se estendido para outros contextos, que não os de irrealis, como em (15):

(15) a. Minha filha convidou pra moça morar com ela.

b. Quando minha mãe estava esperando pra mim nascer.

c. Não me lembrei pra mim pedir meu pai pra te mostrar.

\footnotetext{
2 A autora esclarece que se trata de dados reais com distribuição dialetal, encontrados na região Nordeste, em particular no dialeto maranhense.
} 


\section{d. Me esforço pra mim tirá meu diproma ${ }^{3}$.}

A autora argumenta que a construção em (15a) pode ser comparada à construção do tipo Eu disse para ela sair do quarto, com o verbo 'dizer' na oração matriz, em que é possível uma contraparte com controle do objeto Minha filha convidou a moça $a_{i}$ para [_i morar com ela]/ Eu disse a ela [para [__ i sair do quarto]] .

Quanto à oração em (b), como explica Salles (2007), existe a contraparte finita - estava esperando que eu nascesse - e não existe a contraparte finita da construção com controle, embora uma configuração de controle de objeto seja possível com a oração infinitiva - estava $m_{i}$ esperando [__i chegar]. A autora ainda observa que a construção (b) pode ser comparada à construção Meu partido vai defender do voto ser aberto, já que, em ambas, as preposições para/de marcam o efeito de obviação, licenciando a referência disjunta.

As duas últimas construções (c, d), de acordo com Salles (2007), parecem ser inovações no $\mathrm{PB}$, já que apresentam a estrutura preposicionada com sujeito oblíquo correferencial manifesto, a qual pode ser comparada à construção disse para mim tirar o diploma, em que o pronome oblíquo sujeito é também regido pela preposição para.

Dessa forma, o trabalho de Salles (2007) investiga as preposições introdutoras de oração infinitiva como manifestadoras de traços em $\mathrm{C}$ e, mais particularmente em relação à preposição para, defende ter essa preposição traço irrealis, por ser possível a contraparte finita (cf. 15) e traço de efeito de obviação (cf. 8).

Na próxima seção, abordaremos a análise de Kayne (2000) e mais particularmente a de Salles (2007) a fim de reforçar a hipótese de que a preposição introdutora de oração infinitiva não carrega traços de marcação de Caso e manifesta traços de C.

\section{PROPOSTA DE ANÁLISE EM RELAÇÃO À PREPOSIÇÃO INTRODUTORA DE ORAÇÃO INFINITIVA}

Quanto à hipótese inicial em Kayne (2000) de a forma infinitiva ser um núcleo N, e não $\mathrm{D}$, não nos comprometemos com tal análise para o português, pois o nosso interesse neste trabalho é reforçar a hipótese de que preposições funcionais não têm estatuto uniforme, pois apresentam possibilidade de flutuação, conforme demonstrado em (1).

Reforçamos, baseado em Kayne (2000), a hipótese de que a preposição introdutora de oração infinitiva é a manifestação de traços em C, a partir dos dados em (1) e dos dados do italiano (cf. 6).

Além disso, defendemos como hipótese que:

(i) as preposições de e em e com também apresentam traço irrealis e de efeito de obviação (cf. 16), e não só a preposição para, como argumenta Salles (2007):

(16) a. Eu sugeri [dela vir hoje aqui/Eu sugeri que ela viesse aqui.

b. Eu defendi [do voto ser aberto/Eu defendi que o voto fosse aberto.

c. Eu cismei [dele ter algo com isso/Eu cismei que ele tivesse algo com isso.

d. Eu tenho receio [de/em ele ir ao convento/Eu tenho receio (de) que ele vá ao convento.

e. Estou surpreso [de/em/com ele ir a tua festa/Eu estou surpreso (de) que ele vá a tua festa.

\footnotetext{
${ }^{3}$ Conforme nota da própria autora, "os dados (...) são de falantes não letrados".
} 
f. Maria está esperançosa de/em elas alcançarem o melhor lugar/Maria está esperançosa (de) que elas alcancem o melhor lugar.

Observe-se em (16) que todas as orações licenciadas pela preposição de têm correlato finito irrealis e são todas licenciadas por sujeitos diferentes na oração principal e na encaixada. Tais dados nos revelam que a preposição de, em e com também carregam traços irrealis e de efeito de obviação, não sendo exclusivos da preposição para.

(ii) a diferença entre a preposição para e de, em e com está no fato de que é possível sempre extrair a semântica de finalidade nos casos em que o infinitivo é licenciado pela preposição para, algo que não ocorre com as preposições de, em e com (cf. 17):

(17) a. Eu disse para Maria fazer isso/Eu disse a Maria para fazer isso/Eu disse a Maria (para) que fizesse isso.

b. Daniel pediu para ele ir embora/Daniel pediu a ele para ir embora/Daniel pediu a ele (para) que fosse embora.

c. Quando minha mãe estava esperando pra mim nascer/Quando minha mãe estava me esperando pra nascer/ me esperando (para) que eu nascesse.

d. Não me lembrei pra mim pedir meu pai pra te mostrar/não me lembrei de pedir para o meu pai te mostrar/de pedir (para) que meu pai te mostrasse.

e. Maria convidou pra moçar ficar com ela/Maria convidou a moça para ficar com ela/Maria convidou a moça * (para) que ficasse com ela.

É possível extrair, como dito, de todos os exemplos acima uma semântica subjacente de finalidade, algo que não ocorre em relação às preposições $d e, e m$ e com, já que não é possível a inserção dessas ultimas em nenhum dos exemplos acima. Sendo assim, o aspecto que distingue tais preposições é muito mais semântico do que funcional.

(iii) a lexicalização do traço irrealis e de efeito de obviação não é obrigatória nos casos em que o verbo não exige complemento preposicionado (cf. 18):

(18) a. Eu sugeri (d)ele ir na padaria.

b. Eu defendi (d)o voto ser aberto.

c. Ela desejou (d)ele ir lá.

Em (18), pode-se observar que a lexicalização dos traços formais relacionados à preposição está relacionada também ao verbo que a seleciona. Nos casos acima, é possível supor preposição nula, já que o traço irrealis e o efeito de obviação são possíveis.

Tendo discutido tais questões, defendemos, por fim, que as preposições de, em e com não são marcadoras de Caso, pois apresentam comportamento diferente da preposição comumente conhecida como marcadora de Caso, isto é, aquelas em ambientes nominais puros, pois as que licenciam infinitivo são mais abertas a flutuações do que as que estão diante de DPs, conforme inicialmente demonstrado (cf. 1).

A partir dessa constatação, nos apoiamos na análise de Kayne (2000) no sentido de que dados do italiano apontam para uma distinção entre a preposição marcadora de Caso e aquela que introduz orações infinitivas, por meio de exemplos trazidos pelo autor em relação à seleção da preposição nos ambientes nominais e infinitivos e ao uso da preposição com verbos inacusativos na forma infinitiva. 
Para reforçar ainda mais a hipótese, seguimos Salles (2007), em que se demonstram aspectos formais da preposição para, alguns dos quais estendemos nesta análise para de, em e com em orações completivas infinitivas, por apresentarem semelhanças de traços irrealis e ocuparem, como defendemos, a posição em $\mathrm{C}$ responsável por licenciar complementos infinitivos, não carregando, no entanto, a semântica de finalidade que a preposição para carrega.

Diante de traços específicos das preposições introdutoras de oração infinitiva e disparidades de comportamento em relação a ambientes nominais em que há marcação de Caso, defendemos neste artigo que as preposições funcionais podem se subdividir em dois grupos: (i) as introdutoras de oração infinitiva e não marcadoras de Caso e (ii) as licenciadoras de NPs/DPs e marcadoras de Caso.

\section{CONSIDERAÇÕES FINAIS}

Apresentamos esse trabalho, com base em Kayne (2000) e Salles (2007), a fim de elucidar que a preposição introdutora de oração infinitiva apresenta aspectos formais, como os de irrealis, bem como o papel de introduzir oração infinitiva, traços gramaticais que elucidam melhor o comportamento encontrado nos dados do português brasileiro, para os quais a análise de marcação de Caso não traz respostas, a nosso ver, satisfatórias.

Dessa forma, as preposições funcionais para, de, em e com todas aparentam carregar traços irrealis, na possibilidade de contraparte finita no modo subjuntivo, e introduzem orações infinitivas, sendo a preposição para a única que carrega a semântica de finalidade nos exemplos trazidos neste artigo.

Não está claro, no entanto, qual a relação entre a preposição e o verbo que a antecede em ambientes infinitivos, pois, como se pôde observar nos exemplos trazidos neste artigo, em alguns casos, há uma aparente dissociação entre verbo e preposição, como naqueles em que a forma infinitiva aparece com uma preposição diferente daquela que este exige diante de sintagmas determinantes, e, em outros, há uma estreita ligação, como nos exemplos em que há uma coincidência de uso opcional/obrigatório da preposição diante de infinitivo quando há uma opcionalidade/obrigatoriedade de uso da preposição no complemento do verbo.

Por fim, este artigo abre espaço para questões a serem mais bem desenvolvidas no âmbito da Teoria Gerativa, especialmente na Teoria do Caso, na relação entre verbo e preposição e no estudo da complementação oracional e não oracional nas línguas românicas.

\section{REFERÊNCIAS}

ABNEY, Steven. The English noun phrase in its sentential aspect. Dissertação de Doutorado - MIT, 1987.

CHOMSKY, N. Lectures on Government and Binding. $5^{\text {th }}$ ed. Holland, Foris Publications, 1981.

KAYNE, R. Parameters and Universals. Cambridge: Cambridge University Press, 2000.

MACHADO, Daniel. Preposições introdutoras de orações infinitivas. Dissertação de Mestrado - Universidade de Brasília, 2013. 
NUNES, J. Preposition Insertion in the Mapping from Spell-out to PF, 2008. Disponível em:

https://publishup.uni-potsdam.de/opus4ubp/frontdoor/deliver/index/docId/3057/file/lip28 Btr05.pdf. Acesso em: 8 mar. 2020.

OUHALLA, Jamal. Introducing transformational grammar - from rules to principles and parameters. Great Britain: British Library,1994.

RAPOSO, E.P. Case theory and Infl-to-Comp: the inflected infinitive in European Portuguese. Linguistic Inquiry, v. 18, n. 1, p. 85-109, 1987.

SALLES, H. Preposições essenciais do Português. Dissertação de Mestrado -Universidade de Brasília, 1992.

SALLES, H. Preposições complementadoras: distribuição e propriedades sintáticosemânticas. Encontro Nacional do GT-Teoria da Gramática da ANPOLL, 2007.

Recebido em: 28 de fevereiro de 2019

Aceito em: 28 de fevereiro de 2020

Publicado em Maio de 2020 